\title{
Assessment of Sinonasal Anatomical Variants using 128-Slice MDCT in Patients with Chronic Rhinosinusitis
}

\author{
Anitha Christina Mathuram ${ }^{1}$, Senthil Kumar Aiyappan ${ }^{2}$, Shivani Agarwal ${ }^{3}$, Nair Harikrishnan Raveendran \\ Valsala ${ }^{4}$, Vinayagam Shanmugam ${ }^{5}$ \\ ${ }^{1}$ Junior Resident, Department of Radiodiagnosis, ${ }^{2}$ Professor, Department of Radiodiagnosis, ${ }^{3}$ Junior Resident, Department \\ of Radiodiagnosis, ${ }^{4}$ Junior Resident, Department of Radiodiagnosis, ${ }^{5}$ Professor and Head of the Department, Department of \\ Radiodiagnosis, SRM Medical College Hospital and Research Centre, Kattankulathur, Kanchipuram, Tamilnadu, India
}

Corresponding author: Senthil Kumar Aiyappan, Professor, Department of Radiology, SRM Medical College Hospital and Research Centre, Kattankulathur, Kanchipuram, Tamilnadu-603203, India

DOI: http://dx.doi.org/10.21276/ijcmsr.2019.4.2.27

How to cite this article: Anitha Christina Mathuram, Senthil Kumar Aiyappan, Shivani Agarwal, Nair Harikrishnan Raveendran Valsala, Vinayagam Shanmugam. Assessment of sinonasal anatomical variants using 128-slice MDCT in patients with chronic rhinosinusitis. International Journal of Contemporary Medicine Surgery and Radiology. 2019;4(2):B120-B126.

\section{A B S T R A C T}

Introduction: To investigate the prevalence of anatomic variants of the sinonasal cavities using 128-slice-Multidetector CT and to determine their relation to sinonasal mucosal disease.

Material and methods: A total of 200 patients were included. The inclusion criteria were patients with clinical symptoms of chronic rhinosinusitis and e exclusion criteria were patients with history of trauma, sinus surgery and sinonasal tumours and patients with contraindications for $\mathrm{CT}$ like pregnancy. All the patients with symptoms of chronic rhinosinusitis underwent CT on a 128-MDCT with field of view of $16 \mathrm{~cm}$ from roof of frontal sinus till floor of maxillary sinus with reconstruction of $0.625 \mathrm{~mm}$. The study was acquired in axial plane and coronal, sagittal reconstructions were made.The CT scans was evaluated for the presence of anatomic variants of the sinonasal cavities and associated sinusitis.

Results: The paranasal sinus anatomical variants are highly variable as proved by various previous studies. In our study the most common anatomical variant was deviated nasal septum, followed by agger nasi and concha bullosa. There was no statistically significant correlation between any of these anatomical variants and chronic rhinosinusitis in our study.

Conclusion: The paranasal sinus anatomical variants are highly variable. In our study, the most commonest anatomical variant was deviated nasal septum, followed by agger nasi and concha bullosa. There was no statistically significant correlation between any of these anatomical variants and chronic rhinosinusitis in our study.

Keywords: Nasal Septum; Concha Bullosa; Agger Nasi; Pneumatization

\section{INTRODUCTION}

Paranasal sinuses (PNS) are the air containing cavities in skull that surround the nasal cavity. The paranasal sinuses include maxillary, ethmoid, frontal and sphenoid sinuses. ${ }^{\mathbf{1 , 2}}$ The main functions of paranasal sinuses include lightening of skull, air humidification and voice resonance. ${ }^{3-5}$ There are various imaging modalities available for the evaluation of the paranasal sinuses. Conventional radiography has limited role in the evaluation of nasal cavity, ethmoid and sphenoid sinuses because osteomeatal complexes are not delineated by conventional radiography.

Computed tomography (CT) is the gold standard investigation for the evaluation of paranasal sinus diseases. The pneumatisation and development of paranasal sinuses starts in embryonic life during third to fifth gestational months and ends in early adulthood. There are many unknown factors which can change this pattern and can lead to anatomical variants. There are many sinonasal anatomic variants which can be easily detected by $\mathrm{CT}$ scan. ${ }^{6-8}$ Few of the common anatomical variants are Agger nasi cells, nasal septal deviation, infraorbital ethmoidal cells which are called hallers cell, spheno-ethmoidal cells which are called onodi cells, pneumatised uncinateprocess, paradoxical middle turbinate and concha bullosa. ${ }^{8}$ Few of the other less common anatomical variants are uncinate process pneumatisation, pneumatized crista galli large ethmoidal bullae and supraorbital cells.

A group of disorders characterized by inflammation of the mucosa of the paranasal sinuses is referred as Chronic rhinosinusitis (CRS). Computed tomography (CT) scans are the gold standard diagnostic modality of nose and paranasal sinus diseases. ${ }^{9-14}$ There are many studies regarding the anatomic variations leading to pathogenesis of chronic rhinosinusitis. Some of the anatomic variants have been reported to be associated with chronic rhinosinusitis, possibly leading to inflammation by obstructing drainage pathways from the sinuses and nasal cavity. ${ }^{15-17}$ However, a number of other studies did not show a significant association between these anatomic variants and rhinosinusitis. 
Since there are varied views with regarding to associations between sinonasal anatomical variants and rhinosinusitis in the literature this study was proposed. ${ }^{18-19}$ The purpose of this study is to investigate the prevalence of sinonasal anatomic variants and to determine their relationship to chronic rhinosinusitis. Very few Indian studies are available for associations between anatomical variants and rhinosinusitis and this study also established the prevalence of sinonasal anatomical variants in suburban population of kancheepuram district, Tamilnadu.

\section{MATERIAL AND METHODS}

The study was conducted after getting clearance from institutional ethical committee. Written informed consent was obtained from all patients prior to the study procedure or data collection. This was a prospective study and was done in the Department of Radiodiagnosis, SRM medical college hospital and research centre from the period of January 2017 to July 2018. 200 patients with chronic rhinosinusitis was enrolled in the study.

The inclusion criteria were patients with clinical symptoms of chronic rhinosinusitis like facial pain/pressure, nasal obstruction, nasal discharge/discoloured postnasal drip, hyposmia/anosmia, purulence in examination, acute fever, headache, dental pain, fatigue, cough and ear pain/pressure/ fullness. The exclusion criteria were patients with history of trauma, sinus surgery and sinonasal tumours, pediatric patients less than 12 years, patients with contraindications for CT like pregnancy.

All the patients with symptoms of chronic rhinosinusitis underwent CT on a 128-MDCT (Optima CT 660, GE health care) with field of view of $16 \mathrm{~cm}$ from roof of frontal sinus till floor of maxillary sinus with reconstruction of $0.625 \mathrm{~mm}$. The study was acquired in axial plane and coronal, sagittal reconstructions. The CT scans was evaluated for the presence of anatomic variants of the sinonasal cavities and associated sinusitis.

The anatomical variants which were analyzed in this study include nasal septal deviation, concha bullosa, haller cell, Onodi cell, agger nasi cell, accessory maxillary ostium, bulla ethmoidalis. Uncinate process pneumatization, septations within sphenoid, septations within maxillary sinus, pneumatized superior and inferior turbinate, supraorbital cell, cribriform plate types, crista gali pneumatisation anterior clinoid pneumatisation, pterygoid process pneumatisation, hard palate pneumatisation, sinus hypoplasia, sphenoid sinus extension into posterior nasal septum, dehiscent lamina papyracea. The patients was grouped into two categories. Category 1 was those considered to have minimal to no apparent paranasal sinus disease and category 2 was those who have evidence of clinically significant paranasal sinus disease. Minimal disease is defined as less than 1-mm mucosal thickening with no obstruction of the sinus and its drainage passages. Significant disease is defined as more than $1 \mathrm{~mm}$ mucosal thickening with evidence of obstruction. The prevalence of each variant and its bilateralism was calculated. The degree of paranasal sinus and nasal cavity disease were also assessed.

\section{STATISTICAL ANALYSIS}

Data was analyzed using the SPSS version 22 software. The prevalence of anatomic variants of the paranasal sinuses and nasal cavity was calculated for each group, and the results for the two groups were compared by fischer exact test. The proportion of bilateral anatomic variants was calculated for each of the two groups when applicable, and the results for the two groups was subsequently compared by fischer exact test. For all components conducted in this study, $p$ value less than 0.05 was considered to be statistically significant.

\section{RESULTS}

A total of 200 patients who presented to the Department of radiology, SRM medical College Hospital with diagnosis of chronic sinusitis were enrolled in the study. Among 200 patients enrolled in the study 116 were males and 84 were females. The age group range of the patients were from 1160 years. The youngest patient was 11 year old and the oldest patient was 60 year old. The maximum number of patients with sinusitis were among the age group of 20 - 30 years accounting to $31 \%$ of the total cases. Most common clinical complaints were headache and sneezing accounting for $29 \%$ and $23 \%$ respectively. In the study all the patients had at least one anatomical variants.

In our study 22 anatomical variants of paranasal sinus were evaluated. Among the anatomical variants deviated nasal septum, bony nasal spur, agger nasi, accessory maxillary

\begin{tabular}{|c|c|c|c|c|c|}
\hline \multirow[t]{2}{*}{ Variants } & \multicolumn{2}{|c|}{ Minimal/No sinusitis } & \multicolumn{2}{|c|}{ Significant sinusitis } & \multirow[t]{2}{*}{$P$ value } \\
\hline & No & $\%$ & No & $\%$ & \\
\hline Deviated nasal septum & 93 & 68.38 & 47 & 73.44 & 0.6 \\
\hline Bony septal spur & 66 & 48.53 & 30 & 46.88 & 0.6 \\
\hline Concha bullosa & 47 & 34.56 & 15 & 23.44 & 0.3 \\
\hline Concha lamella & 17 & 12.50 & 5 & 7.81 & 0.6 \\
\hline Agger nasi & 47 & 34.56 & 19 & 29.69 & 0.4 \\
\hline Haller cell & 3 & 2.21 & 2 & 3.13 & 0.3 \\
\hline Onodi cell & 13 & 9.56 & 5 & 7.81 & 0.7 \\
\hline Pneumatised uncinated process & 4 & 2.94 & 2 & 3.13 & 0.6 \\
\hline Accessory maxillary ostium & 35 & 25.74 & 18 & 28.13 & 0.7 \\
\hline Pneumatised anterior clinoid & 21 & 15.44 & 12 & 18.75 & 0.8 \\
\hline Paradoxical mdidle turbinate & 25 & 18.38 & 14 & 21.88 & 0.5 \\
\hline
\end{tabular}




\begin{tabular}{|c|c|c|c|c|c|c|}
\hline \multicolumn{2}{|l|}{ Sinus } & \multicolumn{2}{|c|}{ Minimal } & \multicolumn{2}{|c|}{ Significant } & \multirow{2}{*}{$\begin{array}{c}\text { P value } \\
0.6\end{array}$} \\
\hline Deviated nasal septum & Nil & $\frac{\text { No }}{43}$ & $\begin{array}{c}\% \\
31.62\end{array}$ & $\begin{array}{c}\text { No } \\
17\end{array}$ & $\begin{array}{c}\% \\
26.56\end{array}$ & \\
\hline & Single & 91 & 66.91 & 45 & 70.31 & \\
\hline & Bilateral & 2 & 1.47 & 2 & 3.13 & \\
\hline \multirow[t]{3}{*}{ Concha bullosa } & Nil & 89 & 65.44 & 49 & 76.56 & \multirow[t]{3}{*}{0.3} \\
\hline & Single & 28 & 20.59 & 9 & 14.06 & \\
\hline & Bilateral & 19 & 13.97 & 6 & 9.38 & \\
\hline \multirow[t]{3}{*}{ Concha lamella } & Nil & 119 & 87.50 & 59 & 92.19 & \multirow[t]{3}{*}{0.6} \\
\hline & Single & 12 & 8.82 & 3 & 4.69 & \\
\hline & Bilateral & 5 & 3.68 & 2 & 3.13 & \\
\hline \multirow[t]{3}{*}{ Agger nasi } & Nil & 89 & 65.44 & 45 & 70.31 & \multirow[t]{3}{*}{0.4} \\
\hline & Single & 20 & 14.71 & 5 & 7.81 & \\
\hline & Bilateral & 27 & 19.85 & 14 & 21.88 & \\
\hline \multirow[t]{3}{*}{ Haller cell } & Nil & 133 & 97.79 & 62 & 96.88 & \multirow[t]{3}{*}{0.3} \\
\hline & Single & 0 & 0.00 & 1 & 1.56 & \\
\hline & Bilateral & 3 & 2.21 & 1 & 1.56 & \\
\hline \multirow[t]{3}{*}{ Onodi cell } & Nil & 123 & 90.44 & 59 & 92.19 & \multirow[t]{3}{*}{0.7} \\
\hline & Single & 3 & 2.21 & 2 & 3.13 & \\
\hline & Bilateral & 10 & 7.35 & 3 & 4.69 & \\
\hline \multirow[t]{2}{*}{ Pneumatised uncinated process } & Nil & 132 & 97.06 & 62 & 96.88 & \multirow[t]{2}{*}{0.6} \\
\hline & Single & 4 & 2.94 & 2 & 3.13 & \\
\hline \multirow[t]{3}{*}{ Accessory maxillary ostium } & Nil & 101 & 74.26 & 46 & 71.88 & \multirow[t]{3}{*}{0.7} \\
\hline & Single & 18 & 13.24 & 11 & 17.19 & \\
\hline & Bilateral & 17 & 12.50 & 7 & 10.94 & \\
\hline \multirow[t]{3}{*}{ Pneumatised anterior clinoid } & Nil & 115 & 84.56 & 52 & 81.25 & \multirow[t]{3}{*}{0.8} \\
\hline & Single & 15 & 11.03 & 9 & 14.06 & \\
\hline & Bilateral & 6 & 4.41 & 3 & 4.69 & \\
\hline \multirow[t]{3}{*}{ Paradoxical middle turbinate } & $\mathrm{Nil}$ & 111 & 81.62 & 50 & 78.13 & \multirow[t]{3}{*}{0.8} \\
\hline & Single & 21 & 15.44 & 11 & 17.19 & \\
\hline & Bilateral & 4 & 2.94 & 3 & 4.69 & \\
\hline
\end{tabular}

\begin{tabular}{|c|c|c|}
\hline Variants & & $P$ value \\
\hline \multirow[t]{2}{*}{ Deviated nasal septum } & Right & 0.4 \\
\hline & Left & 0.5 \\
\hline \multirow[t]{2}{*}{ Concha bullosa } & Right & 0.6 \\
\hline & Left & 0.03 \\
\hline \multirow[t]{2}{*}{ Agger nasi } & Right & 0.6 \\
\hline & Left & 0.6 \\
\hline \multirow[t]{2}{*}{ Haller cell } & Right & 0.7 \\
\hline & Left & 0.6 \\
\hline \multirow[t]{2}{*}{ Onodi cell } & Right & 0.6 \\
\hline & Left & 0.5 \\
\hline \multirow[t]{2}{*}{ Pneumatised uncinate process } & Right & 0.5 \\
\hline & Left & 0.5 \\
\hline \multirow[t]{2}{*}{ Accessory maxillary ostium } & Right & 0.3 \\
\hline & Left & 0.3 \\
\hline \multirow[t]{2}{*}{ Pneumatised anterior clinoid } & Right & 0.9 \\
\hline & Left & 0.5 \\
\hline \multirow[t]{2}{*}{ Paradoxical middle turbinate } & Right & 0.3 \\
\hline & Left & 0.9 \\
\hline
\end{tabular}

ostium and concha bullosa were the most common anatomical variants. The least common variant were haller cell, pneumatised uncinate process, dehiscent lamina papyraceae, maxillary sinus septa, pneumatized superior turbinate. Among the study population, $32 \%$ of the participant had MDCT evidence of chronic sinusitis and $68 \%$ had no $/$ mild sinusitis irrespective of presence or absence of anatomical variants.

The most common anatomical variant was found to be deviated nasal septum accounting for $40 \%$ on left side and $32 \%$ on right side. Among the patients with deviated nasal septum $136(68 \%)$ patients had septal deviation on single side and 4 of them (2\%) had bilateral deviation -'S' shape. Minimal /no sinusitis was seen in 93 (68.3\%) and significant sinusitis was seen in $47(73.4 \%)$ patients with the $\mathrm{P}$ value of 0.6 which is statistically insignificant(Table1).Hence no statistically significant correlation was found between chronic sinusitis and deviated nasal septum.

The Second most common anatomical variant was agger nasi with overall prevalence of $50.2 \%$. Its bilateral occurrence was assessed accounting for $25 \%$ on left side and $28.50 \%$ on right side. Among the patients with agger nasi minimal /no sinusitis was seen in 47 (34.5\%) patients and significant sinusitis was seen in $19(29.6 \%)$ patients with the $\mathrm{P}$ value of 0.4 (Table 1). Hence no statistically significant correlation was found between chronic sinusitis and agger nasi.

The third most common anatomical variant was concha 


\begin{tabular}{|c|c|c|c|c|}
\hline SI no & Study & Year & Population & No of variants evaluated \\
\hline 1. & Kim HJ et al. ${ }^{13}$ & 2006 & 113 & 6 \\
\hline 2. & Nouraei SA et $\mathrm{al}^{36}$ & 2009 & 278 & 6 \\
\hline 3. & Smith KD et al. ${ }^{5}$ & 2010 & 883 & 4 \\
\hline 4. & AlkireBCet al. ${ }^{37}$ & 2010 & 36 & 4 \\
\hline 5 & Shpilberg KA et al. ${ }^{16}$ & 2015 & 192 & 20 \\
\hline 5. & Devimeenal Jagannathan et al ${ }^{38}$ & 2017 & 200 & 22 \\
\hline
\end{tabular}

bullosa accounting for $19.50 \%$ on left side and $24 \%$ on right side with the $P$ value of 0.03 and 0.6 respectively. Unilateral concha bullosa was found in 37 patients $(18.5 \%)$ and bilateral concha bullosa was found in 25 patients (12.5\%). Minimal / no sinusitis was seen in $47(34.5 \%)$ and significant sinusitis was seen in $15(23.4 \%)$ patients with the $\mathrm{P}$ value of 0.3 (Table-1). Hence no statistically significant correlation was found between chronic sinusitis and concha bullosa.

The fourth most common anatomical variant is accesory maxillary ostium accounting for $19.50 \%$ on left and $19 \%$ on the right side with the $\mathrm{P}$ value of 0.3 on both the sides. Minimal /no sinusitis was seen in 35 (25.7\%) and significant sinusitis was seen in 18 (28.1\%)patients with the $\mathrm{P}$ value of 0.3 (Table 1). Whether the variants were unilateral or bilateral, there were no statistical correlation between them and chronic sinusitis with insignificant $\mathrm{P}$ value (Table-2). Similarly there was no statistical correlation whether the variants were right sided or left sided (Table-3).

Among the four sinuses hypoplasia of sinus was found to be more common in frontal sinus accounting for $2 \%$. Most common bilateral variant is agger nasi accounting for $20.5 \%$, followed by concha bullosa accounting for $12.5 \%$ and accessory maxillary ostium accounting for $12 \%$. Among the types of olfactory fossa, type II was the most common type accounting for $64 \%$ followed by type I $21 \%$ and type III $5.5 \%$.

\section{DISCUSSION}

Chronic rhinosinusitis is a disorder which is caused mainly due to anatomical blockage, infections or allergy which affects the quality of life significantly of more than 5\% of the population. According to the literatures, some of the region in paranasal sinus are at risk for injuries with consequential intra-operative complications. ${ }^{6}$ Hence the knowledge on these paranasal sinus anatomical variants is essential for endoscopic surgeons as well as for radiologists for preoperative evaluation and in order to avoid iatrogenic complications. ${ }^{6}$ Some of these variants are found to be associated with chronic rhinosinusitis, possibly by obstructing drainage pathways from the sinuses and nasal cavity. Many studies have emphasized that certain anatomic variations forming the lateral wall of the nose are very important and can thereby increase the risk of sinus mucosal disease. ${ }^{8}$ Appropriate radiologic imaging and accurate interpretation of anatomical variants play an important role in the diagnosis and management of these chronic rhinosinusitis. $\mathrm{CT}$ depicts excellent anatomical soft tissue and bony details and helps in the diagnosis, and gives detailed sinonasal anatomy for surgery. ${ }^{12} \mathrm{CT}$ help in evaluating the extent of sinus disease and helps in knowing the anatomical variations and its vital relations with the paranasal sinuses. CT scan assists the surgeon as a "road map" during functional endoscopic sinus surgery. ${ }^{7}$

In our study, we have observed about $31 \%$ of the total cases affected with chronic rhinosinusitis were in the age range of 20-30 years. Surapaneni $\mathrm{H}$ et $\mathrm{al}^{20}$ in the year 2016 conducted a study to determine the underlying cause, clinical features and the impact of treatment on chronic rhinosinusitis patients and had observed that $41.7 \%$ of patients with chronic rhinosinusitis fell in the age group $16-30$ yrs similar to our study. Another study conducted by Gibelli $\mathrm{D}^{1}$ et al reported that the affected age group of chronic rhinosinusitis were in the age range of $21-40$ years accounting for $65.3 \%$ of their study population. In our study, the affected age group of chronic rhinosinusitis were found to be $51 \%$ in the age range of 21 to 40 years. In most of the published literatures the affected age group of chronic rhinosinusitis was found to be 20 to 40 years similar to our study.

In our study, males were more commonly affected with chronic rhinosinusitis accounting for $58 \%$ and females accounted for $42 \%$. This is similar to the study conducted by Surapaneni $\mathrm{H}$ et $\mathrm{al}^{20}$ which had reported the incidence of male candidates affected to be $60 \%$ and females $40 \%$. Most of the previous studies performed by vinodhini $\mathrm{P}^{21}$, Dua et $\mathrm{a}^{22}$, Iseh et $\mathrm{al}^{23}$, Gibelli $\mathrm{D}$ et $\mathrm{al}^{1}$, had showed male preponderance with $66 \%, 57.5 \%, 52 \%$ and $63 \%$ respectively. Surapaneni $\mathrm{H}$ et $\mathrm{a}^{20}$ had demonstrated that the age or gender does not play any significance for causing chronic rhinosinusitis especially with upper respiratory tract infection. Moreover, the paper had concluded that $\mathrm{CT}$ scans to be valuable tool in diagnosing the disease. A recent study conducted in the year 2017 by Kranti Gouripur ${ }^{24}$ on the incidence of sinonasal anatomical variations in South India population associated with chronic sinusitis by $\mathrm{CT}$ scan had reported that both the males and female gender are equally affected with chronic rhinosinusitis disease.

In the study conducted by sandhu et $\mathrm{a}^{25}$ in 2017 , the most common clinical symptoms were nasal obstruction (96\%), nasal drip (84\%), headache (72\%) and sneezing (60\%). In our study population, the majority of the chief complaints of patients with chronic rhinosinusitis were headache (29\%) followed by sneezing (23\%).

Our study yielded similar results to the study conducted by murthy et al. ${ }^{26}$ In our study deviated nasal septum (72\%) and concha bullosa (33.5\%) were the most common variants. How ever, in our study agger nasi was found in $53.5 \%$ of 
patients, but in their study only $8 \%$ of patients had agger nasi. Soraia Ale Souza et anterolateral ${ }^{27}$ in the year 2008 evaluated olfactory fossa depth on 200 coronal computed tomography studies of paranasal sinuses according to the Keros classification. In the study, type II olfactory fossae was most frequently found in $73.3 \%$ of cases and then by type I in $26.3 \%$ and then by type III in $0.5 \%$ of cases. This is in agreement with our study in which type II olfactory fossae was most frequently found in $64.5 \%$ and then by type I found in $21 \%$ and type III found in $5.5 \%$ of our study population. In a recent study conducted by Pradeep kumar et $a 1,{ }^{28}$ in the year 2016, among the four paranasal sinuses, hypoplasia was more common in frontal sinus accounting for $17 \%$ with bilateral involvement in 3\%. In the same study hypoplastic sphenoid sinus was found in $3 \%$ of cases and hypoplasia of maxillary sinus was found in $2 \%$ of cases. This is similar to our study which also showed frontal sinus hypoplasia to be more common accounting for $2 \%$ followed by maxillary sinus and sphenoid sinus accounting for $1 \%$ each. The literature also states that the diagnosis of sphenoid sinus hypoplasia is potentially important in patients in whom trans-sphenoidalhypophysectomy is contemplated. In our study $1 \%$ of cases were found to have hypoplastic sphenoid sinus.

In our study, among all the anatomical variants deviated nasal septum is the most common variant, found in 142 study population accounting for $71 \%$ of cases. Most of the recent previous studies by Mohammad Adeel et al (2013) ${ }^{11}$, Aramani A et al (2014) $)^{15}$, Suri $\mathrm{N}$ et al $(2016)^{29}$ had also showed that deviated nasal septum as most common anatomical variant accounting for $26 \%, 74.1 \%$ and $75 \%$ respectively. In a study done by Mamtha et $\mathrm{al}^{30}$ prevalence of deviated nasal septum in chronic rhinosinusitis cases was reported to be $60 \%$ and $65 \%$ respectively. In our study deviated nasal septum to left was more common than to right side, accounting for $40 \%$ on left side and $32 \%$ on right side. Similar to our study, the study done by Moorthy $\mathrm{P}$ et $\mathrm{al}^{31}$ in the year 2014 showed deviation of nasal septum to left side (54\%) more common than right side $(36.5 \%)$. Though deviated nasal septum is the most common anatomical variant there is no statistical evidence of relation with sinusitis in our study with $p$ value of 0.6 (insignificant). This is similar to the study conducted by Sumaily I et al. ${ }^{32}$ The author studied the relation between deviated nasal septum and paranasal sinus pathology. The study concluded that there is no significant association between deviated nasal and paranasal sinusitis.

The second most common anatomical variant in our study was agger nasi, seen in 107 of the study population accounting for $53.5 \%$. In our study, agger nasi was the most common bilaterally involved variant followed by concha bullosa and accessory maxillary ostium accounting for 25(12.5\%) and $24(12 \%)$ respectively. Bilateral involvement as seen in $20.5 \%$ and unilateral involvement was seen in $12.5 \%$.In a study conducted by Shpilberg KA et al ${ }^{16}$ (2015), agger nasi was the second most common bilateral anatomical variant with prevalence of $70.6 \%$. There are no other studies done on demonstrating the bilaterality of paranasal anatomical variants. Literatures have shown that enlarged agger nasi might lead to sinusitis by narrowing the frontal recess. In our study there is no statistical correlation of agger nasi with sinusitis with insignificant $\mathrm{p}$ value of 0.4 . But few other recent studies conducted by Espinosa W et $\mathrm{al}^{33}$ (2018), Kaya $\mathrm{M}$ et $\mathrm{al}^{34}$ showed statistically significant relationship between agger nasi cells in causing chronic sinusitis.

The third most common anatomical variant is concha bullosa which was found in 87 study population with prevalence of $43.5 \%$ of cases. In our study there is no statistical relation of concha bullosa with sinusitis which has insignificant $p$ value of 0.6.This is in correlation with another recent study done in Mar 2018 by Raja Kalaiarasi et al. ${ }^{35}$ The study was done to investigate the variations of the concha bullosa, based on paranasal sinus imaging, and its possible association with sinusitis. The study concluded that there was no statistically significant association between any types of middle turbinate concha with sinusitis.

Other anatomical variants which are of surgical importance was included in our study, such as onodi cell, haller cell, anterior clinoid pneumatization and dehiscent lamina papyraceae. The prevalence of onodi cell was $15.5 \%$, haller cell was $5.2 \%$, anterior clinoid pneumatization was $10.5 \%$ and dehiscent lamina papyraceae was $1.5 \%$.

There was no statistically significant correlation between any of these anatomical variants and chronic rhinosinusitis in our study, as in previous studies mentioned in table-4.

\section{Limitations:}

The anatomical variants association with one another not studied. Though several variations of uncinate process exists like medial and lateral deflection, we studied only pneumatization of uncinate process. The groups were divided based on the imaging findings and not on clinical symptoms. Not all anatomical variants described in the literature studied.

\section{CONCLUSION}

The paranasal sinus anatomical variants are highly variable as proved by various previous studies. In our study, the most commonest anatomical variant was deviated nasal septum, followed by agger nasi and concha bullosa. There was no statistically significant correlation between any of these anatomical variants and chronic rhinosinusitis in our study. The important anatomical variants to be included in the report include onodi cells, anterior clinoid process pneumatization, supraorbital cells, haller cells, dorsum sella pneumatization and lamina papyracea dehiscence.

\section{REFERENCES}

1. Gibelli D, Cellina M, Gibelli S, Oliva AG, Termine $\mathrm{G}$, Sforza C. Anatomical variants of sphenoid sinuses pneumatisation: A CT scan study on a Northern Italian population. Radiol Med.2017;122(8):575-580.

2. Roman RA, Hedeşiu M, Gersak M, Fidan F, Băciuţ G, Băciuţ M. Assessing the prevalence of paranasal sinuses anatomical variants in patients with sinusitis using Cone Beam Computer Tomography. Clujul Med. 2016;89(3):419-21.

3. Simmen D, Jones N. The endoscopic examination, anatomical variants and special circumstances. Laryngorhinootologie. 2014;93(8):573-7.

4. Al-Abri R, Bhargava D, Al-Bassam W, Al-Badaai Y, 
Sawhney S. Clinically significant anatomical variants of the paranasal sinuses. Oman Med J. 2014;29(2):110-3.

5. Smith KD, Edwards PC, Saini TS, Norton NS. The prevalence of concha bullosa and nasal septal deviation and their relationship to maxillary sinusitis by volumetric tomography. Int J Dent. 2010;2010. pii: 404982.

6. Piskunov IS,Emel'ianova AN.Variants of the anatomical structure of frontal sinuses based on the results of $\mathrm{X}$-ray computed tomography. Vestn Otorinolaringol. 2011;(1):16-21.

7. Robinson M, Donlon D, Harrison H, Houang M, Stammberger H, Wolf G. Variations of the paranasal sinuses in Melanesians as observed by CT. Rhinology. 2010;48(1): 11-7.

8. BâldeaV,Indrei A,Ciupilan C,Scutariu MD.Anatomical variations of landmarks in endoscopic surgery of the paranasal sinuses revealed by MRI imaging. Rev Med Chir Soc Med Nat Iasi. 2010;114(2):490-503.

9. Rocha de Miranda CMN, de Miranda Maranhão CP, Rocha Arraes FMN, Padilha IG, Gomes de Farias LDP, de Araujo Jatobá MSD et al. Anatomical variations of paranasal sinuses at multislice computed tomography: what to look for. Radiol Bras vol.44 no.4 São Paulo July/ Aug. 2011.

10. Tiwari R, Goyal R. Study of Anatomical Variations on $\mathrm{CT}$ in Chronic Sinusitis. Indian J Otolaryngol Head Neck Surg. 2015;67(1):18-20.

11. Adeel M, Rajput MS, Akhter S, Ikram M, Arain A, Khattak YJ. Anatomical variations of nose and paranasal sinuses; CT scan review. J Pak Med Assoc. 2013;63(3):317-9.

12. Chakraborty P, Jain RK, Joshi P, Kumari R, Pradhan S. Anatomic Variations of the Nose in Chronic Rhinosinusitis: Correlation between Nasal Endoscopic and Computerized Tomography Scan Findings and a Review of Literature. Clin Rhinol An Int J 2016;9(1):13-17.

13. Kim HJ, Jung Cho M, Lee JW, et al. The relationship between anatomic variations of paranasal sinuses and chronic sinusitis in children. Acta Otolaryngol 2006; 126(2):1067-1072.

14. Fadda GL, Rosso S, Aversa S, et al. Multiparametric statistical correlations between paranasal sinus anatomic variations and chronic rhinosinusitis. Acta Otorhinolaryngol Ital 2012; 32(1):244-251

15. Aramani A, Karadi RN, Kumar S. A Study of Anatomical Variations of OsteomeatalComplex in Chronic Rhinosinusitis Patients-CT Findings. J Clin Diagn Res. 2014;8(10):KC01-4

16. Shpilberg KA, Daniel SC, Doshi AH, Lawson W, Som PM. CT of Anatomic Variants of the Paranasal Sinuses and Nasal Cavity: Poor Correlation With Radiologically Significant Rhinosinusitis but Importance in Surgical Planning. AJR Am J Roentgenol. 2015;204(6):1255-60.

17. Mendiratta V, Baisakhiya N, Singh D, Datta G, Mittal A, Mendiratta P. Sinonasal Anatomical Variants: CT and Endoscopy Study and Its Correlation with Extent of Disease. Indian J Otolaryngol Head Neck Surg. 2016;68(3):352-8.

18. VarshneyH,VarshneyJ,Biswas S, Ghosh SK.Importance of CT Scan of ParanasalSinuses in the Evaluation of the Anatomical Findings in Patients Suffering from
Sinonasal Polyposis. Indian J Otolaryngol Head Neck Surg. 2016;68(2):167-72.

19. Wu J, Jain R, Douglas R. Effect of paranasal anatomical variants on outcomes in patients with limited and diffuse chronic rhinosinusitis. Auris Nasus Larynx. 2017;44(4):417-421.

20. Surapaneni H, Sisodia SS. Aetiology, diagnosis and treatment of chronic rhinosinusitis: a study in a teaching hospital in Telangana. Int J Otorhinolaryngol Head Neck Surg 2016;2(4):14-7.

21. Vinodhini P, Bhat S, Sree Ram MN. Anatomical Variations of the Nose and Paranasal Sinuses in Palakkad Population Using CT Scan - A Case Control Study. Online J Health Allied Scs. 2017;16(1):6.

22. Dua K, Chopra H, Khurana AS, Munjal M. CT scan variations in chronic sinusitis. Indian journal Radiol imag. 2005;15(3):315-20.

23. Iseh KR, Makusidi MM. Rhinosinusitis; A retrospective analysis of clinical pattern and outcome in north western Nigeria Ann Afr med. 2010;9(1):20-6.

24. Gouripur K, Udaya Kumar M, Anand B. Janagond, Elangovan S, Srinivasa V.Incidence of sinonasal anatomical variations associated with chronic sinusitis by CT scan in Karaikal, South India. Int J Otorhinolaryngol Head Neck Surg. 2017;3(3):576-580.

25. Sandhu S, Gupta V, Matreja PS. Clinicotherapeutic Profile of Patients Suffering from Sinusitis. J Transm Dis Immun. 2017, 1:1.

26. Murthy DD,Rao BRC, Rao SSP. Analytical Study of Anatomical Variations of Nose And Pns in Ct Scan And Chronic Sinusitis.IOSR Journal of Dental and Medical Sciences (IOSR-JDMS) 2016;15(7):30-35.

27. Soraia Ale Souza, Marcia Maria Ale de Souza et al. Computed tomography assessment of the ethmoid roof: a relevant region at risk in endoscopic sinus surgery. Radiol Bras vol.41 no.3 São Paulo May/June 2008.

28. Pradeep Kumar, Rakesh BS et al.,Anatomical Variations of Sinonasal Region, A Coronal CT Scan Study, International Journal of Contemporary Medical Research september 2016.

29. Suri N, Janardan T, Parmar H. Correlation of anatomical variations of Paranasal sinuses and Chronic Rhinosinusitis. IAIM, 2016; 3(12):8488.

30. Mamtha H, Shamasundar NM, Bharathi MB, Prasanna LC. Variations of osteomeatal complex and its applied anatomy: a CT scan study. Indian J Sci Technol.2010;3(4):904-07.

31. Moorthy, P., Kolloju, S., Madhira, S. and Jowkar, A. Clinical Study on Deviated Nasal Septum and Its Associated Pathology. International Journal of Otolaryngology and Head \& Neck Surgery 2014; 3(6):75-81.

32. Ibrahim Sumaily, Jibril Hudise, Saud Aldhabaan. Relation between deviated nasal septum and paranasal sinus pathology. Int J Otorhinolaryngol Head Neck Surg. 2017;3(4):786-790.

33. Espinosa W, Genito R, Ramos RZ. Anatomic variations of the nasal cavity and paranasal sinus and their correlation with chronic rhinosinusitis using Harvard staging system. J Otolaryngol ENT Res. 2018;10(4):190-193.

34. Kaya M, Çankal F, Gumusok M, Apaydin N, Tekdemir 
I. Role of anatomic variations of paranasal sinuses on the prevalence of sinusitis: Computed tomography findings of 350 patients. Niger J Clin Pract 2017;20:1481-8.

35. Raja Kalaiarasi, Venkataramanan Ramakrishnan, Santhosh Poyyamoli. Anatomical Variations of the Middle Turbinate Concha Bullosa and its Relationship with Chronic Sinusitis: A Prospective Radiologic Study. Int Arch Otorhinolaryngol. 2018; 22(03): 297-302.

Source of Support: Nil; Conflict of Interest: None

Submitted: 23-03-2019; Accepted: 25-05-2019; Published online: 15-06-2019 